\title{
Experience and the Hit Rate for Entrepreneurial Initiatives
}

\author{
Kimberly M. Green \\ Department of Management, Richards College of Business, University of West Georgia, GA, USA
}

\begin{abstract}
The hit-rate perspective on innovation contends that firms cannot improve their success rates and, so, can increase their number of successes only by making more attempts. On the other hand, an organizational learning perspective suggests that firms can increase proficiency with processes they perform repeatedly. Basing hypotheses on these two perspectives, this study considers how a firm's percentage of launches, or hits, from its new product development (NPD) portfolio is related to characteristics of its on-going NPD activity. The setting is drug development in the pharmaceutical industry, and the analysis uses panel data for 77 firms over the years 1997 - 2006. The launch rate measure considers that drugs either are launched or are dropped from the portfolio when development is discontinued. Results reveal a negative relationship between the number of projects in the portfolio and the launch rate. There is an inverted-U curvilinear relationship between the percentage of projects that are newly initiated and the launch rate. The test of an interaction indicates that launch rate decreases with increases in the percent of new projects in knowledge categories that are new to the firm. These results imply that project portfolios characterized by activity that is a stretch from the base of experience tend to exhibit lower launch rates.
\end{abstract}

Key Words: corporate entrepreneurship, innovation, new product development, organizational learning, panel data, pharmaceutical industry

\section{Introduction}

While research shows that the success rate for innovation and entrepreneurial initiatives is not high, it offers conflicting views on whether firms can improve their success rates. On one hand, the "hit rate" or "atbats" argument contends that firms cannot improve their hit rate for starting new businesses or introducing new products, so they increase their number of successes only by taking more turns at bat (Morris \& Kuratko, 2002; Peters, 1990; Roberts, 1980). On the other hand, learning theory tells us that firms can increase their proficiency with processes that are performed repeatedly and that organizations vary in their rates of learning (Argote, 1999). Existing research has found evidence of an innovation competence or capability (e.g., Calantone, Cavusgil \& Zhao, 2002; Quintana-Garcia \& Benavides-Velasco, 2008). Yet there is a gap in our understanding of how a firm's hit rate with entrepreneurial initiatives varies with its number of attempts.

The innovation hit rate, or success rate, has important implications. If concerns over losses lead to attempts to avoid failure, the firm will also avoid learning (Corbett, Neck \& DeTienne, 2007; McGrath, 1999). If firms can learn from past failures and improve the chances of future endeavors, then the hit rate may contribute to perceptions of learning efficacy (Garrett, Covin \& Slevin, 2009). Sitken
(1996) suggests that repeated success can lead to delusions that everything is fine even if the process could benefit from adjustments. Anecdotal evidence suggests that a series of misses can dampen employees' enthusiasm for persisting or managers' interest in allocating resources for innovation, while a string of hits may build a firm's confidence or attract investors (Kanter, 2006). The present study seeks to contribute to understanding of the success rate with innovation by examining factors that influence the success rate for firms that routinely undertake entrepreneurial initiatives. New product development (NPD) offers a useful framework for examining success rates, particularly in industries in which NPD efforts are continuous. One such context is the pharmaceutical industry in which research and development is on-going and the introduction of new products is a key basis for competition. This study focuses on launch rate as an outcome measure for the NPD process, defining launch rate as the percentage of NPD initiatives that are launched as products rather than discontinued while in development. In the hypotheses developed in the following section, experience with NPD is indicated by the number of products under development. The influence of category-specific experience is also considered by examining whether launch rate is influenced by undertaking new product initiatives in knowledge categories that are new to the firm. 


\section{Theory and Hypotheses}

A variety of measures have been used for investigating the productivity of a firm's innovation process. Research has considered innovativeness, innovative proficiency, innovative competence, innovative efficiency, innovative effectiveness, launch proficiency, NPD productivity, innovative capability, and success rate (Alegre, Chiva \& Lapiedra, 2009; Calantone et al., 2002; Cooper \& Edgett, 2008; Henderson \& Cockburn, 1994; Lin \& Chen, 2005; Langerak, Hultink \& Robben, 2004; Pearce \& Ensley, 2004; Peters 1990; Quintana-Garcia $\&$ Benavides-Velasco, 2008). In many cases, these are not competing measures of the same construct but measures of different components of the innovation process. For example, operationalizations include calculations such as output relative to dollars input, speed to market for those products that reach the market, and commercialization success after launch (Cooper \& Edgett, 2008; Nerkar \& Roberts, 2004). "Launch rate" in this paper presents additional information by measuring the number of launches relative to the number of attempts. In general, the NPD process ends for a product when one of two outcomes occurs - either the product is launched or the firm ceases development of the product. The "launch rate" (i.e., percentage of NPD outcomes that are launches) would be a measure of the success rate of the development process.

Studies of product success rates typically consider the post-launch commercial success of the products; they do not consider those products that might also have been under development but never reached the market. By examining the launch rate, this study offers insight into a stage of the NPD process that has received limited attention. Further, few existing studies actually measure success rate (for one example, see Danzon, Nicholson \& Pereira, 2005) because it is often difficult to obtain the data on failures which are necessary for computing success rate. This launch rate measure contributes to cumulative knowledge about innovation productivity because of its relationship with the other measures that consider factors such as expenditures and development speed. For example, the portion of launch rate represented by the projects that are never launched has generated expenditures but no offsetting revenues and may have delayed the launch of more promising projects by competing for resources.

A common theme of each construct is the role of knowledge and learning as a factor contributing to innovation productivity. Learning theory relates experience to performance through the learning curve or experience curve in which performance improves as experience increases but, typically, at a decreasing rate (Huber, 1991). Just as there are a variety of approaches for measuring success, different measures of experience have been used. Organizational experience is reflected in the age of the firm (Calantone et al., 2002), in the years of industry experience of the firm's management team (Smith et al., 2005), or as cumulative activity (Danzon et al., 2005). While these measures represent general experience, measures indicative of more specific experience have also been studied. Experience in product categories (Nerkar \& Roberts, 2004) and in phases of development (Danzon et al., 2005) has been found to influence NPD success. Evidence has also been found that the age or recency of the experience impacts NPD outcomes, although in some cases more recent knowledge promotes innovation while in other cases older knowledge promotes innovation (Katila, 2002).

Taking a broad view of success rates for entrepreneurial initiatives in general, some management theorists suggest that the success rate does not differ greatly across firms. Using a baseball analogy to explain the "hit rate" or success rate of companies developing new products or new businesses, they argue that the firms with a larger number of successes simply make more attempts or take more turns at bat (Morris \& Kuratko, 2002; Peters, 1990). Peters (1990: 17) argues that "innovation, in the end and no matter how well thought out, is a numbers game." In this view, a greater number of attempts yields a greater total number of successes but also a greater number of failures.

An alternative view is suggested by research focused on organizational learning. Learning is evidenced by increasing proficiency and decreasing variation in performance (Levinthal \& March, 1993). The learning curve links increases in experience or practice to improvements in performance (McKee, 1992). Theorists suggest that learning is not limited to repetitive task situations, such as increasing production efficiencies, but that organizations can learn to innovate (McKee, 1992) and can become more proficient at the process of developing new products or new businesses (Tidd \& Taurins, 1999). In situations of repeated innovative activity such as continuous NPD, firms have the opportunity to refine their routines and codify their best practices. Codification and documentation of the process preserves learning from past product development efforts and facilitates the sharing of learning across new initiatives (Kim \& Wilemon, 2007; Zander \& Kogut, 1995). In this view, those firms making more attempts to develop new products could have a higher launch rate as a result of learning more than firms that make fewer attempts. 
Learning takes place over time, and an increase in an activity may initially result in increased failures. However, research suggests that organizations can learn from failure (McGrath, 1995; McKee, 1992) and that the knowledge gained from new product failures contributes to subsequent successes (Maidique \& Zirger, 1985). If the accumulated knowledge from both successes and failures can improve the likelihood of future successes, then a firm's new product development launch rate should improve as the number of attempts increases. Using learning theory as a foundation, this study hypothesizes that higher levels of NPD activity will be associated with higher NPD launch rates. The expected positive relationship between development activity and NPD launch rate is stated in the following hypothesis:

Hypothesis 1 (H1): The size of the product development portfolio (number of products under development) is positively related to NPD launch rate.

Hypothesis 1 is stated as a linear relationship. However, the learning curve that associates experience and performance is traditionally presented as a curvilinear relationship that exhibits diminishing returns to experience (Huber, 1991). Once performance reaches a certain level of proficiency, it becomes increasingly difficult to improve performance even with further increases in experience. Using this perspective, beyond some threshold portfolio size, improvements to launch rate would be increasingly difficult to achieve even if additional experience was obtained by increasing the number of products in the development portfolio. Danzon et al. (2005) found some evidence of this form of relationship in a study showing large, positive and diminishing returns to experience for late-stage trials in pharmaceutical development. R\&D productivity may also suffer when a company has too many projects underway because resources are stretched too thinly, projects are not prioritized, or the mix of projects is inappropriate (Cooper \& Edgett, 2008). A hypothesis specifying a curvilinear relationship between the number of products under development and the NPD launch rate (taking an inverted-U shape) is offered as an alternative to the linear relationship expressed in $\mathrm{H} 1$.

Alternate Hypothesis 1 (H1A): The relationship between the size of the product development portfolio (number of products under development) and the NPD launch rate is curvilinear, exhibiting an inverted-U shape.

The NPD process consists of several sequential stages, and projects are typically evaluated at each stage to determine if they are deserving of continued resource allocation (Tonkens, 2005). There is evidence that knowledge is stage-specific (Danzon et al., 2005). For example, some firms are adept at identifying viable candidates for development (Henderson \& Cockburn, 1996), and some demonstrate proficiency with the set of activities required to launch a product (Langerak et al., 2004). Firms may have a large quantity of activity if they frequently introduce products to the pipeline but rarely launch them. These firms would have significant experience with early stages and limited experience with later stages. If newly initiated projects represent a large percentage of a firm's development portfolio, the opportunity for cumulative learning at later stages of development may be reduced, particularly in product development processes that span many years. Scale and scope have been identified as contributors to productivity in product development (Cockburn \& Henderson, 2001; Ding \& Eliashberg; Lin \& Chen, 2005). Much of the benefit of scale and scope is generated by synergies across projects and by applying lessons learned in one project to other projects. However, building scale by always having a large percentage of projects that are new may reduce the scale efficiencies. It may be difficult to focus development activity sufficiently to draw the necessary connections between prior experience, existing knowledge, and the current market opportunity. Projects at the same stage of development will compete for necessary physical resources as well as knowledge resources such as researchers' time and management attention.

At the other extreme, having too few newly initiated projects in the portfolio could also offer limited chances for improving launch rate. Research suggests that, in pharmaceutical product development, firms use narrower pipelines than they should and that broader pipelines would increase the likelihood of launching successful products (Ding \& Eliashberg, 2002). A pipeline that is being managed for optimum productivity will have projects at various stages of development (Cooper, Edgett \& Kleinschmidt, 1999; Ding \& Eliashberg, 2002). Knowledge depreciates over time (Argote, 1999); so if the early stages of the development process receive limited attention, the process knowledge for navigating the early stages depreciates. A mid-range value for the portion of the portfolio that is represented by newly initiated projects may offer the best chance for letting the firm examine a critical mass of new projects without overextending itself. A hypothesis specifying a curvilinear relationship between the percentage of newly initiated projects in the portfolio and the NPD launch rate (taking an inverted-U shape) is offered:

Hypothesis 2 (H2): There is a negative curvilinear relationship (inverted-U shape) between the percentage of products in the portfolio that are newly active and the NPD launch rate. 
The effect of the percentage of new projects in the portfolio could be contingent on portfolio size. The evidence of knowledge transfer across product lines (Argote, 1999) suggests that there are benefits of increasing portfolio size. In fact, research has shown that reducing scale of activities was associated with reduced performance. However, those activities were primarily ones in which knowledge could be embedded in technology, such as automobile production (Argote, 1999; Epple et al., 1996). While NPD is a replicable process, the outputs vary considerably more than for a manufacturing process. Still, the benefits of knowledge spillovers across development projects in portfolios have been found to exist in pharmaceutical NPD (Cockburn \& Henderson, 2001; Henderson \& Cockburn, 1996). Such benefits are not without limits, however, as effective NPD utilizes cross-functional efforts for sharing knowledge which involve considerable time and complexity of coordination (Calantone et al., 2002; Cooper \& Edgett, 2008; Pearce \& Ensley, 2004). Even though knowledge and experience are not depleted with use, the associated resources necessary for putting the knowledge to use are limited. Due to demands on researchers and their time and on facilities such as labs and test markets that cannot be used by all projects simultaneously, many new projects may be canceled. A high percentage of new projects in the pipeline could matter more for large portfolios due to the expected increase in the complexity of managing the portfolio and allocating resources.

The potential benefits of knowledge spillovers across a large number of new projects may also be diminished if many of the project ideas that are new at the same time were proposed in pursuit of the same market opportunity. A number of such projects may not be sufficiently different from each other to capture a different market and revenue base. This problem would be particularly acute in large portfolios, for which a large percentage of new projects implies a large number of new projects. Research also suggests that senior management is often involved at the earliest stages of a project's development, and this involvement has been associated with lower creativity of the development projects (Harmancioglu, McNally, Calantone \& Durmusoglu, 2007). This lower level of creativity suggests that those development projects are similar to current products and, therefore, based more on exploitation of existing knowledge than on exploration. If the projects that are selected to survive the earliest stages of development are the less innovative projects, many of these might be canceled at later stages if it is ultimately determined that they are not sufficiently different from existing products to generate adequate revenue and justify launching. These arguments suggest that a high percentage of new projects in the pipeline would be more detrimental to large portfolios in terms of the launch rate realized from that portfolio. This expected relationship is expressed in the following hypothesis:

Hypothesis 3: The relationship between the percentage of products in the portfolio that are newly active and the NPD launch rate is moderated negatively by the size of the product development portfolio (number of products under development). As the size of the product development portfolio increases, the relationship between the percentage of newly active products and the NPD launch rate becomes more negative.

In addition to managing the number of products under development, firms can vary the number of distinct knowledge areas in which they attempt to develop products. One framework that has been advocated for organizing a new product portfolio is based on strategic categories where the resource allocation decision across different categories is driven largely by the strategy of the business (Cooper et al., 1999). Examples of strategic categories are types of projects, markets, or product lines. From a learning perspective, these different categories represent different knowledge bases (DeCarolis \& Deeds, 1999; Henderson \& Cockburn, 1994). In the pharmaceutical industry, the strategic categories for drugs are therapeutic classes which differ in terms of the medical conditions being treated. The nature of and treatments for depression, for example, are different from those for high blood pressure. Knowledge is more similar within a product category than between categories (Henderson \& Cockburn, 1994).

Knowledge and capabilities are category-specific (Thomke \& Kuemmerle, 2002). Success probabilities for new products have been found to vary across categories of drug development (Danzon et al., 2005). Henderson and Cockburn (1994) reported that firms that maintained an extensive flow of information between therapeutic classes had more productive drug discovery efforts. Beneficial spillovers of knowledge (Henderson \& Cockburn, 1996) both among projects in the same category and across product categories are likely to increase as development activity within each category increases. Synergies would be expected both within and between categories in which the firm had built experience. However, adding new categories to the portfolio takes the firm into unfamiliar territory. The addition of new categories involves the development of new knowledge and capabilities.

Theory suggests that improvements in the overall launch rate for the NPD process are more likely if the firm focuses its NPD activity in a small 
number of categories. By focusing in a few categories, the organization's “ability to learn to innovate" is accelerated (McKee, 1992: 243). Conversely, switching among skill bases reduces the rate at which the organization learns to innovate based on that skill and requires a ramp-up period in the new skill base (McKee, 1992). Further, a firm's absorptive capacity is a function of the firm's level of prior related knowledge. If a new product is related to an existing knowledge base, the extent of knowledge development that is required is small (Kazanjian, Drazin \& Glynn, 2002) and the firm can more quickly realize the benefits of its knowledge (Zahra \& George, 2002). On the other hand, a firm that begins activity in a new category has little absorptive capacity in that category. With low absorptive capacity, the firm has limited ability to recognize the value of new information, to assimilate it, and to apply it (Cohen \& Levinthal, 1990). If the ability to acquire and utilize knowledge is low, the firm will have a correspondingly low NPD launch rate. These points support the hypothesis that not just new activity but new activity in new knowledge categories will have a detrimental effect on NPD launch rate. The percentage of products that are in new categories is, therefore, offered as a negative moderator of the relationship between the percentage of products newly under development and the NPD launch rate.

Hypothesis 4: The relationship between the percentage of products in the portfolio that are newly active and the NPD launch rate is moderated negatively by the percentage of products in the portfolio that are in new knowledge categories.

\section{Methods}

\section{Research setting}

Researchers have indicated that single-industry studies are effective methods for studying NPD processes because they control for industry-specific factors (Calantone, Vickery \& Droge, 1995). NPD studies relying on single industries include investigations of industries such as pharmaceuticals, robotics, optics, chemicals, mobile communications, and film (Ganesan, Malter \& Rindfleisch, 2005; Haefliger, Jager \& von Krogh, 2010; Jaspers, Prencipe \& Ende, 2012; Katila \& Ahuja, 2002; Zahay, Griffin \& Fredericks, 2011). The standardization of development phases and the consistency of classification categories due to the regulatory requirements make pharmaceuticals a useful setting for NPD research. This industry runs on new products, and competitors are continually engaged in NPD activity (Takayama,
Watanabe \& Griffy-Brown, 2002). Pharmaceutical data have been widely used in studies of the management of innovation to investigate topics such as stages and speed of development, cooperative development and alliances, knowledge spillovers between categories, and the scale and scope of the product pipeline (e.g., Bierly \& Chakrabarti, 1996; Cockburn \& Henderson, 2001; Danzon et al., 2005; McGrath \& Nerkar, 2004; Nerkar \& Roberts, 2004; Takayama et al., 2002; Thomke \& Kuemmerly, 2002). The pharmaceutical industry is the setting for the present study.

Researchers examining the management of innovation generally distinguish three common phases of an innovation process: discovery, development, and deployment (Henderson \& Cockburn, 1994; Malnight, 2001). These phases can be associated with, respectively, the science, technology, and productmarket functions along the firm's value chain $(\mathrm{Li}$, Vanhaverbeke \& Schoenmakers, 2008). Drug data are useful for investigating these three broad stages of new product development (Henderson \& Cockburn, 1994; Roberts \& McEvily, 2005; Thomke \& Kuemmerle, 2002). At each stage, it is possible to define "successes" and "failures." The first stage is the research or discovery process in which "successes" are discoveries of potentially effective therapies and compounds that then proceed to be tested. Next, the development process involves the testing of products and selection of those that will be launched. A "success" would be a product that was launched, while a "failure" would be a drug that was never launched because its development was discontinued. The final stage is the post-launch performance, and "successes" in this stage are commercial successes.

The present research concentrates on the middle stage, or the development of the new product from the time it is identified as a potentially viable candidate up until the point of launch. During this stage, development may be discontinued and a product not launched for a variety of reasons. For example, if it is determined that the product will not represent a sufficient improvement over products already on the market, the new product might not be expected to prompt customers to switch and, therefore, might not generate enough revenue to justify continued development and launch. Or, a firm may find that it would be difficult to scale production to serve a large enough market and, so, development is discontinued and the product never launches. Drug candidates in the development stage proceed through a specified set of testing phases that are defined consistently across all firms in the industry (e.g., Phase I trials, Phase II trials, etc.) (Danzon et al., 2005). Consequently, all firms within the 
pharmaceutical industry are subject to similar development constraints. Issues such as time-tomarket and cost of development are impacted by the drug testing and marketing regulations which are administered, in the United States for example, by the Food and Drugs Administration (FDA) (Tonkens, 2005). By focusing on the pharmaceutical industry, this study controls for variations in the level of innovation and new product development activity which might differ in different industries.

\section{Data and sample}

The data for this study were gathered from the Adis R\&D Insight database of drug development activity, Compustat, firm annual financial reports and SEC $10-\mathrm{K}$ filings. The Adis R\&D Insight database is a product of Wolters Kluwer Health that is used by pharmaceutical firms as a tool for competitor analysis. Sources for the data include scientific and medical publications, press releases, trade events, conferences, and clinical trial study assessments. Pharmaceutical firms are periodically asked to review their profiles for accuracy. The profiles include the full drug portfolio of each company - basic research programs, drugs under development (listed by stage of development), drugs discontinued during some phase of development, and launched drugs. For a random sample of the firms in the present study, a comparison of the portfolios reported in the database with those disclosed by the firms on their websites and in annual reports indicated that the database presents an accurate picture of the firms' portfolios. This database has been used in other studies of pharmaceutical industry productivity and firms' experience in therapeutic categories (Danzon et al., 2005) and identified as a useful source for gauging the potential clinical and economic impact of drug and biologic therapies that are pending FDA approval (Andes, 2008).

This study focuses on the drug development activity for the period 1997 to 2006 . For this study, a firm's NPD portfolio is defined to include launched drugs and drugs that are actively under development. A minimum portfolio size of 15 active products was set for inclusion in this study because the values of key variables such as portfolio breadth would have limited meaning for portfolios consisting of only one or two drugs. Drugs were included in a firm's product portfolio only if the firm was included in the list of originators for the drug. Including only those drugs that the firm had a role in initiating (either alone or cooperatively) and excluding drugs that were acquired or in-licensed in later development stages are criteria consistent with this study's focus on the ability of firms to move products through the development process.

The database included 281 companies. Applying these selection criteria yielded a dataset consisting of 90 firms and 7,524 drugs. There are 77 firms for which data is available on all variables of interest in this study. Demographic data indicate that the companies are established firms with a median age of 76 years. Size ranges from 100 to over 110,000 employees. The majority ( $83 \%$ on average) of the drugs in the portfolios of the firms in this study are under development, indicative of the continuous nature of NPD in this industry.

The development status of each drug in each year is used in the computation of the portfolio variables. It is not uncommon for one drug to be developed to treat potentially more than one medical condition. In the terminology of the industry, these drugs have more than one indication. An outcome or final resolution for a drug's development is that either (a) the drug is launched or (b) the development process is discontinued for all indications. If a drug is launched, the earliest launch date for any indication or in any country is used as the launch date for the drug. For discontinued drugs, the latest "discontinued" date for any indication or any country is recorded as the date development was discontinued for that drug. In cases where a full development history was not available for a drug, no activity was assumed for a given year if the database did not explicitly confirm a drug's status for that year.

\section{Measures}

The following paragraphs describe the operationalization of the dependent, independent, and control variables used in this research.

NPD launch rate. The dependent variable in the analysis is the NPD launch rate which represents the percentage of products that have a "launch" outcome versus a "discontinued" outcome. Drugs classified as "discontinued" for the purpose of this study include those identified in the Adis database with a status of Discontinued, No Development Reported, Suspended, or Withdrawn. The denominator in computing the NPD launch rate is the number of products for which an outcome - either launched or discontinued - has been determined during a specified period of time. That period of time has been set at two years in this study because of a pattern observed in the way discontinued development activity is recorded in the database. Launch dates can be recorded with relative accuracy; however, dates when development is discontinued are generally more difficult to pinpoint. As a result, many drugs in a firm's portfolio may have the same discontinue date because that is the 
date when the pharmaceutical firm confirmed for the database developer the status of the drugs in its portfolio. All drugs discontinued since the last confirmation date may, thus, be assigned a common discontinue date. To smooth the effects of discontinue dates being recorded in this manner, the launch rate variable is computed using a rolling twoyear launch rate.

Number of products under development. The number of products under development represents a firm's current product development activity. In terms of the data on which the proposed study is based, the number of products under development is measured as the total number of the drugs in a firm's portfolio that are currently in any of the development stages (pre-clinical through registration). These are drugs for which a development outcome (i.e., launched or discontinued) has not yet been determined. Danzon et al. (2005) also used counts of drugs to represent total activity or total experience. In the present study, only those drugs that have been assigned a number (e.g., Eli Lilly's LY 295501) or a name (e.g., Enzastaurin) are included in the total. Thus, the total excludes any items specifically identified in the database as research programs because they represent broader and more basic research that could eventually produce any number of drugs (Henderson \& Cockburn, 1996). Further, drugs that have already been launched are not included. The number of drugs in the firm's portfolio is a count including all drugs that are actively under development.

Percentage of the products actively under development that are newly (first-year) active. One way to sub-divide the products that are currently under development is based on how recently they were added to the development portfolio. For each year of the panel dataset, the percentage of products that are newly active is computed as the percentage of the total products in the development portfolio that were added during the current year. The values for this variable range from $0 \%$ to $100 \%$. In the data for this study, a drug is counted as newly active for the first year that its status can be coded as "active". One limitation of this variable is that, as mentioned earlier, a full development history is not available for all drugs. For example, if the earliest date of development activity is available beginning only with the Phase II trials, the drug is recorded as "active" beginning with that date. No activity is assumed for a given year if the database does not explicitly confirm a drug's status for that year.

Percentage of newly active products in new categories. Standardized categories are used by the pharmaceutical industry to classify drugs based on the conditions they treat and their chemical composition. Products and their associated knowledge bases are assumed to be more similar within categories than between categories (Nerkar \& Roberts, 2004). Therefore, the therapeutic categories are used in this study to represent distinct categories of knowledge. It is assumed that development activity within a category will generate experience that is most relevant to future activity within that category rather than another category. The Adis R\&D Insight database reports the World Health Organization's Anatomical Therapeutic Chemical (WHO-ATC) class for each drug. This classification system divides the drugs into groups according to the organ or system on which they act and their chemical, pharmacological and therapeutic properties. The fourteen Level 1 categories are subdivided into a total of 112 categories at Level 2 . Finer sub-divisions of the categories are made through all five levels of the WHO-ATC system (World Health Organization, 2010). For the purpose of this study, the Level 1 classification is used to define the knowledge categories because the categories are sufficiently different from each other to capture specialized and non-overlapping knowledge without being too narrow. The narrower categories beyond Level 1 were assumed to include too much similar knowledge as categories are repeatedly sub-divided.

Adding a new product to the pipeline in a category with which the firm has recent experience is assumed to be a less complex undertaking for the firm than adding a new product in a category with which the firm has no recent experience. In this study, a category was considered to be "existing" for the firm if the firm was pursing development activity in that category currently or if the firm had activity in that category within the past two years. A category was "new" to the firm if the database reported no activity for the firm in that category or if any preceding activity in that category had ceased more than two years ago. This operationalization of "existing" and "new" categories recognizes that knowledge and experience can remain viable and useful for a period of time but that, at some point, prior knowledge and experience will become outdated and will contribute little to future success. This assumption is consistent with previous research that has found that the age of knowledge matters for the usefulness of that knowledge in supporting innovation (Katila, 2002; Katila \& Ahuja, 2002). The percentage of newly active products that are in categories new to the firm is calculated as the total new products in new categories divided by the total new products in all (i.e., existing plus new) categories.

The variables firm size, firm age, $R \& D$ intensity, and firm performance are included in the analysis to 
control for possible alternative explanations for the hypothesized relationships. The operationalization of these variables and their theoretical linkage to the other variables in the study are explained here.

Firm size. Firm size has been linked empirically and theoretically to several of the variables in this study. For example, large firms might have a higher success rate because they may be better able to afford the specialized equipment that is often required by different therapeutic categories (Graves \& Langowitz, 1993). Superior performance in drug development has been attributed to the returns to scope which are achievable by large firms (Cockburn $\&$ Henderson, 2001). Small firms are associated with more innovative products and large firms are associated with less innovative products (Kotabe \& Swan, 1995). These differences in degree of innovativeness pursued by firms of different sizes could affect launch rates achieved by these firms. Firm size is measured as the number of employees.

Firm age. A premise of this study is that a firm's knowledge base influences proficiency with NPD. Because knowledge accumulates over time, older firms will have had more time to build a knowledge base than younger firms. Age has been linked to a firm's ability to innovate (Calantone et al., 2002; Hauser, Tellis \& Griffin, 2006). Firm age is measured as the years since the firm's founding date or date of incorporation when the founding date is not available.

$R \& D$ intensity. Firms with a high level of drug development activity might have a better NPD launch rate not because they are accumulating knowledge and building competences in particular therapeutic categories but because their higher expenditures for R\&D include higher salaries that enable them to attract the best scientists (Henderson \& Cockburn, 1994). R\&D intensity is measured on an annual basis as the firm's R\&D expenditures for the year divided by the annual sales revenue.

Firm performance. Firms with large development portfolios might experience a high launch rate not because of improvements based on experience but because both variables are a consequence of high firm performance. High performance could contribute to a high launch rate if the firm is able to hire the most preeminent scientists or acquire the most advanced equipment. High performance can be associated not only with firms having high launch rates but also with firms having low launch rates who have enjoyed great commercial success with their few launches. High performance can provide resources and slack for initiating more development projects and absorbing the risks of project failures. Alternatively, low performance might be a consequence of a poor launch rate or could simply limit resources available for adding projects to the NPD portfolio. Firm performance is measured as return on assets (ROA).

\section{Analytical techniques}

This study uses NPD portfolio characteristics to explain NPD launch rate. Because the intent of the study is to assess the effect of the firm's knowledge base and NPD portfolio structure existing while a product is being developed, the portfolio structure measures (the IVs) should precede the NPD launch rate measure (the DV) in time. Using measures of the IVs and DV from the same point in time would not account for the realities that product development occurs over time and that the knowledge base and the portfolio traits in existence during a product's development affect the launch/discontinue decision about that product. As described earlier, the NPD launch rate variable is computed on a two-year rolling basis. The first NPD launch rate figure recorded for each company in the dataset is the value for the 1998/1999 two-year period. The 1997 values for the portfolio structure variables are used to explain that 1998/1999 NPD launch rate, and so on.The data used for tests of these hypotheses are structured as panel data - repeated measures of the same firms across consecutive years. A Hausman test indicated that a fixed effects model was preferred because random effects estimators would be biased. Further, based on a test result indicating that autocorrelation is present in these data, the regression models in this study included a Durbin-Watson correction for autocorrelation. Therefore, the results of the tests of the hypotheses are fixed effects estimates that control for autocorrelation across panels. Additionally, time dummy variables were included as recommended by Certo and Semadeni (2006) for analyses of cross-sectionally dominated datasets $(\mathrm{N}>\mathrm{T})$ as is the case for the dataset used in this study $(\mathrm{N}=77 ; \mathrm{T}=7)$. The results were computed using STATA 10.1.

\section{Results}

Table 1 reports the bivariate correlations and summary statistics for the dependent, independent, and control variables. Because some skewness was detected in the distributions of two of the control variables-firm size and firm age - a log transformation of these variables is used in hypothesis testing. The highest correlation among the variables that are central to the hypothesized relationships in this study is the correlation of $r=.41$ between the percent of products that are newly active and the percent of newly active products in new categories. The other relatively high 
correlations reported in Table 1 (i.e., $r>|.60|$ ) all occur among the control variables rather than among the variables that are central to the hypothesized relationships in this study. Because the use of interaction terms in regression can contribute to multicollinearity, the independent variables were centered in the manner suggested by Aiken and West (1991) prior to the computation of the interaction terms in order to minimize correlations between the independent variables and their interaction terms. Variance inflation factors indicated that multicollinearity was not a concern within these data.

Table 2 presents the results of the regression analyses. Model 1 is the base model which includes only the control variables and the year dummies. Model 2 includes the variables that are the focus of the linear relationships expressed in hypothesis 1 (number of products under development) and hypothesis 2 (percent of active products that are newly active). This model also includes the other independent variable (percent of new products in new categories) that is later used to form interaction terms. The $\mathrm{p}$-value $(\mathrm{p}<.05)$ for the number of products under development indicates that there is a significant linear relationship between number of products under development and NPD launch rate; however, the negative coefficient indicates that the direction of the relationship is opposite to that hypothesized in $\mathrm{H} 1$.

Model 3 includes the curvilinear terms for the tests of hypotheses $\mathrm{H} 1 \mathrm{~A}$ and $\mathrm{H} 2$. Alternative Hypothesis 1 (H1A) predicted a negative curvilinear relationship (inverted-U) between the number of products under development and NPD launch rate. The $\mathrm{p}$-value for the coefficient of the squared value of number of products under development is not significant, indicating that $\mathrm{H} 1 \mathrm{~A}$ is not supported by these data. Hypothesis $2(\mathrm{H} 2)$, which predicted a negative curvilinear relationship (inverted-U) between the percent of newly active products and NPD launch rate, is supported by the negative and significant $(\mathrm{p}<.05)$ coefficient for the squared percent of newly active products.

Table 1. Summary statistics and correlation matrix.

\begin{tabular}{|c|c|c|c|c|c|c|c|c|}
\hline Variable & $\begin{array}{l}\text { Mean } \\
\text { (S.D.) }\end{array}$ & 1 & 2 & 3 & 4 & 5 & 6 & 7 \\
\hline 1. Launch Rate & $\begin{array}{r}0.20 \\
(0.30)\end{array}$ & & & & & & & \\
\hline 2. Number of & 30.29 & $-0.10^{* *}$ & & & & & & \\
\hline $\begin{array}{l}\text { Products Under } \\
\text { Development }\end{array}$ & (41.02) & & & & & & & \\
\hline $\begin{array}{l}\text { 3. Percent of } \\
\text { Active Products } \\
\text { that are Newly }\end{array}$ & $\begin{array}{r}0.16 \\
(0.16)\end{array}$ & $0.07^{\dagger}$ & -0.04 & & & & & \\
\hline $\begin{array}{l}\text { Active } \\
\text { 4. Percent of New } \\
\text { Products in New } \\
\text { Categories }\end{array}$ & $\begin{array}{r}0.11 \\
(0.025)\end{array}$ & $0.12^{* * *}$ & $-0.18^{* * *}$ & $0.41^{* * *}$ & & & & \\
\hline $\begin{array}{l}\text { 5. Firm Size } \\
\text { (employees) }^{\mathrm{a}}\end{array}$ & $\begin{array}{r}1.71 \\
(1.84)\end{array}$ & -0.02 & $0.59^{* * * *}$ & $-0.10^{*}$ & $-0.29^{* * *}$ & & & \\
\hline $\begin{array}{l}\text { 6. Firm Age } \\
\text { (years) }^{\mathrm{a}}\end{array}$ & $\begin{array}{r}4.04 \\
(0.91)\end{array}$ & 0.06 & $0.39^{* * * *}$ & $-0.08^{*}$ & $-0.18^{* * *}$ & $0.67^{* * * *}$ & & \\
\hline 7. $R \& D$ Intensity & $\begin{array}{r}0.44 \\
(1.37)\end{array}$ & -0.04 & $-0.11^{* *}$ & $0.09^{*}$ & $0.13^{* * *}$ & $-0.43^{* * *}$ & $-0.38^{* * * *}$ & \\
\hline $\begin{array}{l}\text { 8. Financial } \\
\text { Performance } \\
\text { (ROA) }\end{array}$ & $\begin{array}{r}0.01 \\
(0.21)\end{array}$ & $0.10^{*}$ & $0.23^{* * *}$ & $-0.07^{\dagger}$ & $-0.16^{* * * *}$ & $0.58^{* * *}$ & $0.49^{* * * *}$ & $-0.64^{* * * *}$ \\
\hline
\end{tabular}

$\mathrm{N}=77$ firms

${ }^{a}$ The natural $\log$ of the variables firm size and firm age was used in the analysis.

$\dagger \mathrm{p}<.10 \quad * \mathrm{p}<.05 \quad * * \mathrm{p}<.01 \quad * * * \mathrm{p}<.001$ 
Table 2. Cross-sectional time-series fixed effects estimates ${ }^{a}$

\begin{tabular}{|c|c|c|c|c|}
\hline $\begin{array}{l}\text { Dependent Variable: } \\
\text { NPD Launch Rate }\end{array}$ & Model 1 & Model 2 & Model 3 & Model 4 \\
\hline $\begin{array}{l}\text { Step 1: Controls and Year Dummies } \\
\text { Log Firm Size (employees) } \\
\text { Log Firm Age (years) } \\
\text { R\&D Intensity } \\
\text { ROA } \\
\text { Year_1998 } \\
\text { Year_1999 } \\
\text { Year_2000 } \\
\text { Year_2001 } \\
\text { Year_2002 } \\
\text { Year_2003 }\end{array}$ & $\begin{array}{c}-0.08(.07) \\
0.19(.29) \\
0.01(.01) \\
0.11(.10) \\
0.07(.04) \\
0.02(.05) \\
-0.01(.05) \\
-0.01(.05) \\
0.01(.04) \\
0.03(.04)\end{array}$ & $\begin{array}{c}-0.07(.06) \\
0.28(.28) \\
0.01(.01) \\
0.12(.10) \\
0.10^{*}(.05) \\
0.06(.06) \\
0.03(.05) \\
0.02(.05) \\
0.02(.04) \\
0.03(.04)\end{array}$ & $\begin{array}{c}-0.06(.06) \\
0.29(.28) \\
0.01(.01) \\
0.12(.10) \\
0.09^{*}(.05) \\
0.06(.06) \\
0.04(.05) \\
0.02(.05) \\
0.02(.04) \\
0.03(.04)\end{array}$ & $\begin{array}{c}-0.06(.06) \\
0.26(.28) \\
0.01(.01) \\
0.10(.10) \\
0.09^{\dagger}(.05) \\
0.06(.05) \\
0.03(.05) \\
0.02(.05) \\
0.02(.04) \\
0.04(.04)\end{array}$ \\
\hline $\begin{array}{l}\text { Year_2004 (dropped) } \\
\text { Step 2: Independent Variables } \\
\text { Prods. Under Development } \\
\text { Percent Newly Active } \\
\text { Percent in New Categories }\end{array}$ & & $\begin{array}{c}-0.002^{*}(.001) \\
0.02(.08) \\
0.04(.06)\end{array}$ & $\begin{array}{c}-0.004^{*}(.002) \\
0.17(.11) \\
0.04(.06)\end{array}$ & $\begin{array}{c}-0.003^{*}(.001) \\
0.06(.11) \\
0.08(.06)\end{array}$ \\
\hline $\begin{array}{l}\text { Step 3: Curvilinear Terms } \\
\text { Prods. Under Dev. Squared } \\
\text { Percent Newly Active Squared }\end{array}$ & & & $\begin{array}{c}0.00(.00) \\
-0.50^{*}(.25)\end{array}$ & \\
\hline $\begin{array}{l}\text { Step 4: Two-Way Interaction Terms } \\
\text { Total Prods Under Dev x Percentage } \\
\text { Newly Active } \\
\text { Percentage Newly Active x } \\
\text { Percentage in New Categories }\end{array}$ & & & & $\begin{array}{l}-0.00(.01) \\
-0.57^{* *}(.22)\end{array}$ \\
\hline $\begin{array}{l}\text { Constant } \\
\text { F for model } \\
\text { F test for added variables } \\
\text { R-sq within } \\
\text { R-sq between } \\
\text { R-sq overall }\end{array}$ & $\begin{array}{c}-0.45(.77) \\
0.92 \\
\\
0.02 \\
0.04 \\
0.02\end{array}$ & $\begin{array}{c}-0.82(.78) \\
1.13 \\
1.73 \\
0.03 \\
0.06 \\
0.03\end{array}$ & $\begin{array}{c}-0.82(.78) \\
1.30 \\
2.35^{\dagger} \\
0.04 \\
0.07 \\
0.04\end{array}$ & $\begin{array}{c}-0.73(.78) \\
1.43 \\
3.31^{*} \\
0.05 \\
0.06 \\
0.04\end{array}$ \\
\hline
\end{tabular}

Finally, Model 4 contains the two-way interaction terms that are the focus of hypotheses 3 and 4 . Hypothesis 3 predicted that the percent of newly active products would negatively moderate the relationship between number of products under development and NPD launch rate. The p-value for the interaction term between number of products under development and percent of newly active products is not significant, indicating that there is no support for Hypothesis 3 provided by these data. Hypothesis 4 predicted a moderating relationship that is tested using the interaction term between percent of newly active products and the percent of new products in new categories. The negative and significant $(p<.01)$ coefficient for the interaction term supports Hypothesis 4.

\section{Discussion and Conclusion}

The results of this study give insight into the innovation hit rate, indicating how a firm's hit rate is influenced by the size of its product development portfolio and by its efforts to initiate development projects in knowledge categories that are new to the firm. In this study, the innovation hit rate is operationalized as a launch rate that is measured as the percentage of pharmaceutical drug candidates that complete the development process and are launched to the market.

First, on the premise that the number of products under development is an indicator of the firm's experience with NPD, the expectation was that higher levels of NPD experience would be associated with 
greater proficiency with NPD efforts and that this proficiency would be reflected in higher percentage launch rates. Contrary to both hypotheses $\mathrm{H} 1$ and $\mathrm{H} 1 \mathrm{~A}$, the results indicate a negative linear relationship between the size of the development portfolio and the launch rate. This finding suggests that the experience that comes from the quantity of product development projects does not lead to a higher percentage of those projects becoming launched products. This result is consistent with a study by Danzon et al. (2005) which examined success rates for different phases of drug development trials and found that industry-wide experience had negative effects in the phase 2 and phase 3 trials. Further, increasing portfolio size may increase the complexity of sharing knowledge across projects and limit the benefits of learning for the launch rate in large portfolios. The negative linear relationship between portfolio size and launch rate may also be explained by considering that firms with a high proficiency in launching products will not need to initiate large numbers of projects because these firms start projects that are likely to be launched. The firms making a larger number of attempts might be doing so in order to offset a lower launch rate. This result provides an alternative perspective on the "at-bats" argument, or the contention that firms have similar hit rates and must simply make more attempts if they want to have more products on the market.

Hypothesis 2 proposed a curvilinear relationship in which the lowest launch rates were associated with low and high percentages of new products in the pipeline. The hypothesized inverted-U shaped relationship was confirmed. This result is consistent with research indicating that pipeline structure - the distribution of projects across the stages of the development process - is associated with NPD performance (Ding \& Eliashberg, 2002). If the number of newly initiated projects is too low, the firm has limited opportunities to take advantage of synergies in projects at the same stage. Conversely, too many newly initiated projects place high coordination and knowledge-sharing demands on the early stages of the process. Given the long development time for drugs, a firm with a consistently high percentage of newlystarted projects may frequently discontinue products under development instead of launching them. By frequently undertaking new tasks but completing relatively few, a firm may be limiting the learning that can come from its experience. As the percentage of new initiatives in the portfolio increases, the launch rate eventually decreases. This finding is consistent with research that has found evidence that firms demonstrate proficiency with different stages of the NPD process (Danzon et al., 2005; Henderson \&
Cockburn, 1996; Langerak et al., 2004). This evidence suggests that there is knowledge that is specific to the various stages of the NPD process, since stage-specific measures reveal performance differences.

Hypothesis 3 tested for the presence of an interaction effect between portfolio size and the percentage of newly active projects, but the data provided no support for this hypothesis. Adding the percentage of newly active products to the regression equation as a moderator did not further explain the relationship between the size of the portfolio and the NPD launch rate. An alternative statement of this result is that the relationship between the percentage of newly active projects and the launch rate is not contingent on portfolio size. While the percentage of newly active projects matters (Hypothesis 2), the interaction of percentage and portfolio size does not explain differences in launch rate. Large portfolios may have large numbers of newly active projects, but smaller portfolios that are dealing with a similar percentage of newly active projects are facing challenges of applying knowledge and building experience regardless of the fact that they have fewer total new projects in development. This finding is consistent with research highlighting the complexity of coordinating knowledge-sharing and transferring learning in effective NPD efforts (Calantone et al., 2002; Kim \& Wilemon, 2007; Zander \& Kogut, 1995).

While larger portfolios may offer more opportunities for stage-specific synergies, achieving those synergies is difficult. Another explanation for the finding that the interaction of size of development portfolio and the percentage of newly initiated development projects is not associated with launch rate may be found in a particular strategy for product development based on real options logic. In a real options approach to innovation, a firm makes small, incremental investments in many projects so that the potential of those projects can be assessed before large financial commitments are made (MacMillan, Van Putten, McGrath \& Thompson, 2006; McGrath, 1999; McGrath \& Nerkar, 2004). Projects that are not going to be successes are canceled quickly before unnecessary resources are committed. A low launch rate would result not from a failure to learn from experience but, instead, because maximizing launch rate is not necessarily a goal of the strategy. Researchers suggest that a real options strategy is appropriate for expensive research and development projects that have uncertain outcomes (MacMillan et al., 2006; McGrath, 1999), such as a pipeline of pharmaceutical drugs for which the efficacy of the product or the size of the market may remain in question through many phases of trials. 
Further information about the influence of the percentage of newly active projects in the portfolio is obtained by considering whether those projects were in knowledge categories familiar to the firm or new to the firm. The significant negative interaction in hypothesis 4 indicates that the relationship between the percentage of newly active projects and NPD launch rate is more negative when a greater percentage of new projects are in new knowledge categories. Undertaking new projects in new knowledge categories would arguably be more complex and subject to greater uncertainty than undertaking new projects in categories in which the firm already had experience. This result is consistent with relatedness research indicating that a firm is more likely to experience failure when attempting to start new products or new businesses that are distantly related to what the firm already knows rather than closely related to what the firm already knows. For example, Nerkar and Roberts (2004) found that the effective use of distal (as opposed to proximal) technological experience requires additional, complementary product-market experience and that integrating the two requires a general combinative capability. Since such capabilities are complex to develop, the use of distal experience would be expected to increase a firm's difficulty of succeeding in developing products in new categories.

\section{Implications}

The results of this study have implications for our understanding of the hit rate for entrepreneurial endeavors. First, the results indicate that the innovation hit rate does vary among firms, at least over some spans of time such as the eight years of annual launch rate data examined here. This finding suggests that there will be stretches of time during which some firms will enjoy an advantage deriving from a better-than-average series of initiatives for which the product development expenditures lead to product launches. One explanation is that, even though learning is cumulative, knowledge depreciates over time (Epple, Argote \& Devadas, 1996). Further, knowledge may not be easily transferable across time if it cannot, for example, be embedded in technology or codified to facilitate transfer (Epple et al., 1996). Case-based research and anecdotal evidence suggest that these winning streaks and losing streaks have implications for organizational learning (Kanter, 2006).

This study finds that a high number of innovation attempts is associated with a low hit rate. Therefore, contrary to the at-bats argument, simply increasing the number of attempts does not increase the number of innovation successes. Further, increasing innovation experience through innovation attempts does not increase the percentage of successes. It appears that firms learn at different rates and may learn different things from similar experiences, such as a successful launch or a failed launch. The concept of learning from failure indicates that firms can apply lessons learned from their failures to achieve future successes. Given the results of this study, how is learning from failure manifested?

This study adds to a body of research suggesting that the similarity between the knowledge the firm already possesses and the knowledge required for developing a new product or business has implications for the likelihood of success of that new endeavor. Introducing new knowledge categories into the firm's NPD portfolio has a detrimental impact on the NPD launch rate. General knowledge about the development process for a type of product (e.g., drugs) is not sufficient; category-specific knowledge is also important.

Implications for the management of portfolios of entrepreneurial initiatives can also be derived from this study. It appears that differences in innovation hit rates do exist among firms over some periods of time. Therefore, understanding and managing the periods of success and failure in innovation activities can be a source of competitive advantage. One way to influence the hit rate may be by managing the pipeline in terms of the percentage of projects that are new or that are in new knowledge categories. Category-specific experience contributes to the success of a product development program. When expanding to new categories, firms should expect a reduction in the launch rate. The fact that the hit rate varies suggests that maintaining a consistently high hit rate may not be possible. In fact, maintaining a high rate may not necessarily be desirable, if it causes firms to avoid extending their knowledge into new categories or stretching to pursue valuable opportunities. Based on the results pertaining to size of the project portfolio, it seems that adding projects to the portfolio does not help the launch rate. Firms that can launch a sufficient number of new products that achieve commercial success can be less concerned with the launch rate from the development stage of the process. These firms will apply their experience to finding their appropriate ratio of projects launched to projects undertaken but that ratio will, perhaps, not be high.

Firms should exercise caution if using an innovation hit rate as a performance measure for the corporate entrepreneurship process. The hit rate can be measured at any of several stages of the development process, and the hit rate at one stage 
may not be indicative of success at other stages. However, even if the firm is not formally tracking the hit rate, there will still be a sense within the firm of whether recent efforts have generated more successes or more failures. The hit rate may, thus, have implications for the firm's confidence in its process and abilities to build on its knowledge base and for employees' enthusiasm for innovation.

\section{Limitations and Future Research}

Some limitations of this study should be noted. First, because this study examines only the pharmaceutical industry, the results may not generalize to other industries. However, patterns in this industry may be similar to other high-tech industries that rely on sustained new product development and that have long lead times for development. Second, the computation of key variables is based on the classification of each drug in a firm's portfolio as active (i.e., under development), launched, or discontinued. The full development history is not available for all drugs, however. For these drugs, the date when a drug is newly active is the first date of activity identified in the database, but this date may not be the earliest year that development actually began. When the first date in the database is not the date of earliest activity, the number of products in a firm's portfolio is understated. A third limitation of this research is that the dependent variable of interest NPD launch rate - may be only weakly tied to the commercialization success of the product introductions. This fact is significant because it can be argued that what matters most in NPD efforts is not necessarily a firm's ability to launch individual new products or even the percentage of launches achieved but, rather, the payback from innovation efforts relative to the total costs incurred. Along these lines, however, some research linking product advancement and performance among pharmaceutical firms has shown that those firms with more aggressive knowledge strategies (e.g., firms characterized as innovators or explorers) have higher financial performance than firms with less aggressive strategies (e.g., exploiters) (Bierly \& Chakrabarti, 1996).

This study has revealed additional questions about the innovation hit rate that could be interesting avenues of future research. For example, examining how long each project in a firm's portfolio has been under development can provide insight into the launch rate implications of discontinuing projects quickly versus taking a longer time to assess the merit of projects. Research suggests that firms can learn from failure; but learning from failure can become expensive unless each failed project fails quickly or produces valuable knowledge. Firms that are able to learn from failure with NPD will likely continue to take risks and expect failures because they know that they can learn from those efforts. Examining whether firms exhibit patterns of failures followed by successes can indicate how firms apply knowledge gained from failures. What knowledge from prior failures is applied to future successes?

Future research could also consider whether NPD proficiency is linked to other firm performance measures. This study considered the determinants of NPD launch rate in an organizational learning framework. Extending that investigation to include firm financial performance measures would give insight into how an organizational learning capability can translate into improved financial performance. Learning from experience with NPD may be reflected in measures other than launch rate. Firms can be profitable with a low hit rate if, for instance, one blockbuster product offsets many failures. Financial performance measures could reveal those firms that are proficient at identifying and developing blockbuster products.

A topic central to the field of entrepreneurship is understanding factors that differentiate successful from failed entrepreneurial endeavors. Such research spans the entire entrepreneurial process by distinguishing, for example, those organizations or individuals who identify viable opportunities for new products from those who do not, those who take appropriate action to pursue opportunities, and those who ultimately market commercially successful products. Insight into such questions can be obtained by investigating both the success or failure of individual initiatives and the success rate of firms that repeatedly engage in entrepreneurship and innovation. This study focused on launch rate for a firm's NPD process in an effort to further our understanding of the implications of experience for the success rate of firms undertaking entrepreneurial initiatives.

\section{References}

Aiken, L.S., \& West, S.G. (1991). Multiple regression: Testing and interpreting interactions. Newbury Park, CA: Sage.

Alegre, J., Chiva, R., \& Lapiedra, R. (2009). Measuring innovation in long product development cycle industries: an insight in biotechnology. Technology Analysis and Strategic Management, 21(4), 535-546.

Andes, S.L. (2008). Spotlight on pharmaceutical pipeline database products: A useful resource for PBMs and MCOs. Formulary, 43(11), 420-422.

Argote, L. (1999). Organizational learning: Creating, retaining and transferring knowledge. Norwell, MA: Kluwer Academic Publishers.

Bierly, P. E. \& Chakrabarti, A. K. (1996). Generic knowledge strategies in the U.S. pharmaceutical industry. Strategic Management Journal, 17(Winter SI), 123-135. 
Calantone, R.J., Cavusgil, S.T., \& Zhao, Y. (2002). Learning orientation, firm innovation capability, and firm performance. Industrial Marketing Management, 31, 515-524.

Calantone, R. J., Vickery, S.K., \& Dröge, C. (1995). Business performance and strategic new product development activities: an empirical investigation. Journal of Product Innovation Management, 12(3): 214-223.

Certo, S.T. \& Semadeni, M. (2006). Strategy research and panel data: evidence and implications. Journal of Management, 32(3), 449-470.

Cockburn, I. M., \& Henderson, R. M. (2001). Scale and scope in drug development: unpacking the advantages of size in pharmaceutical research. Journal of Health Economics, 20, 1033-1057.

Cohen, W. M., \& Levinthal, D. A. (1990). Absorptive capacity: A new perspective on learning and innovation. Administrative Science Quarterly, 35, 128-152.

Cooper, R.G. \& Edgett, S.J. (2008). Maximizing productivity in product innovation. Research Technology Management, 51(2), 47-58

Cooper, R. G., Edgett, S.J., \& Kleinschmidt, E. J. (1999). New product portfolio management: practices and performance. Journal of Product Innovation Management, 16(4), 333-350.

Corbett, A. C., Neck, H. M., \& DeTienne, D. R. (2007). How corporate entrepreneurs learn from fledgling innovation initiatives: Cognition and the development of a termination script. Entrepreneurship: Theory \& Practice, 31(6), 829-852.

Danzon, P.M., Nicholson, S., \& Pereira, N.S. (2005). Productivity in pharmaceutical-biotechnology R\&D: The role of experience and alliances. Journal of Health Economics, 24, 317-339.

DeCarolis, D. M., \& Deeds, D. L. (1999). The impact of stocks and flows of organizational knowledge on firm performance: an empirical investigation of the biotechnology industry. Strategic Management Journal, 20, 953-968.

Ding, M., \& Eliashberg, J. (2002). Structuring the new product development pipeline. Management Science, 48(3), 343-363.

Epple, D., Argote, L., \& Devadas, R. (1996). Organizational learning curves: a method for investigating intra-plant transfer of knowledge acquired through learning by doing. In M.D. Cohen \& L.S. Sproull (Eds.), Organizational Learning (pp. 83-100). Thousand Oaks, CA: Sage.

Ganesan, S., Malter, A. J., \& Rindfleisch, A. (2005). Does distance still matter? Geographic proximity and new product development. Journal of Marketing, 69(4), $44-60$.

Garrett, R. P., Covin, J. G., \& Slevin, D.P. (2009). Market responsiveness, top management risk taking and the role of strategic learning as determinants of market pioneering. Journal of Business Research, 62(8), 782-788.

Graves, S.B., \& Langowitz, N.S. (1993). Innovative productivity and returns to scale in the pharmaceutical industry. Strategic Management Journal, 14(8), 593-605.

Haefliger, S., Jager, P., \& von Krogh, G. (2010). Under the radar: industry entry by user entrepreneurs. Research Policy, 39(9), $1198-1213$

Harmancioglu, N., McNally, R.C., Calantone, R.J., \& Durmusoglu, S.S. (2007). Your new product development (NPD) is only as good as your process: an exploratory analysis of new NPD process design and implementation. $R \& D$ Management, 37(5), 399-424.

Hauser, J., Tellis, G.J., \& Griffin, A. (2006). Research on innovation: a review and agenda for Marketing Science. Marketing Science, 25(6), 687-717.

Henderson, R., \& Cockburn, I. (1994). Measuring competence? Exploring firm effects in pharmaceutical research. Strategic Management Journal, 15 (Winter Special Issue), 63-84.

Henderson, R., \& Cockburn, I. (1996). Scale, scope, and spillovers: The determinants of research productivity in drug discovery. RAND Journal of Economics, 27(1), 32-59.
Huber, G.P. (1991). Organizational learning: The contributing processes and the literatures. Organization Science, 2(1), 88115.

Jaspers, F., Prencipe, A., \& Ende, J. (2012). Organizing interindustry architectural innovations: evidence from mobile communication applications. Journal of Product Innovation Management, 29(3), 419 - 431.

Kanter, R.M. (2006). Confidence: How winning streaks and losing streaks begin and end. New York: Three Rivers Press.

Katila, R. (2002). New product search over time: past ideas in their prime? Academy of Management Journal, 45(5), 995-1010.

Katila, R., \& Ahuja, G. (2002). Something old, something new: A longitudinal study of search behavior and new product introduction. Academy of Management Journal, 45(6), 11831194.

Kazanjian, R.K., Drazin, R., \& Glynn, M. A. (2002). Implementing strategies for corporate entrepreneurship: a knowledge-based perspective. In M.A. Hitt, R.D. Ireland, S.M. Camp \& D.L. Sexton (Eds.), Strategic Entrepreneurship: Creating a New Mindset (pp. 173-199). Oxford: Blackwell Publishers.

Kim, J., \& Wilemon, D. (2007). The learning organization as facilitator of complex NPD projects. Creativity and Innovation Management, 16(2), 176-191.

Kotabe, M., \& Swan, K.S. (1995). The role of strategic alliances in high-technology new product development. Strategic Management Journal, 16(8), 621-636.

Langerak, F., Hultink, E.J., \& Robben, H.S.J. (2004). The impact of market orientation, product advantage, and launch proficiency on new product performance and organizational performance. Journal of Product Innovation Management, 21(2), 79-94.

Levinthal, D.A., \& March, J.G. (1993). The myopia of learning. Strategic Management Journal, 14(Winter Special Issue), 95112.

Li, Y., Vanhaverbeke, W., \& Schoenmakers, W. (2008). Exploration and exploitation in innovation: Reframing the interpretation. Creativity \& Innovation Management, 17(2), 107-126.

Lin, B.W., \& Chen, J.S. (2005). Corporate technology portfolios and R\&D performance measures: A study of technology intensive firms. $R \& D$ Management, 35(2), 157-170.

MacMillan, I.C., Van Putten, A.B., McGrath, R.G., \& Thompson, J.D. (2006). Using real options discipline for highly uncertain technology investments. Research Technology Management, 49(1), 29-37.

Maidique, M.A., \& Zirger, B.J. (1985). The new product learning cycle. Research Policy, 14, 299-313.

Malnight, T.W. (2001). Emerging structural patterns within multinational corporations: toward process-based structures. Academy of Management Journal, 44(6), 1187-1210.

McGrath, R.G. (1995). Advantage from adversity: Learning from disappointment in internal corporate ventures. Journal of Business Venturing, 10(2), 121-142.

McGrath, R. G. (1999). Falling forward: real options reasoning and entrepreneurial failure. Academy of Management Review, 24(1), 13-30.

McGrath, R.G., \& Nerkar, A. (2004). Real options reasoning and a new look at the R\&D investment strategies of pharmaceutical firms. Strategic Management Journal, 25, 1-21.

McKee, D. (1992). An organizational learning approach to product innovation. Journal of Product Innovation Management, 9, 232-245.

Morris, M.H., \& Kuratko, D.F. (2002). Corporate entrepreneurship. Fort Worth, TX: Harcourt.

Nerkar, A., \& Roberts, P.W. (2004). Technological and productmarket experience and the success of new product introductions in the pharmaceutical industry. Strategic Management Journal, 25, 779-799.

Pearce, C.L., \& Ensley, M.D. (2004). A reciprocal and longitudinal investigation of the innovation process: The central role of 
shared vision in product and process innovation teams (PPITs). Journal of Organizational Behavior, 25(2), 259-278.

Peters, T. (1990). Part one: Get innovative or get dead. California Management Review, 33(1), 9-26.

Quintana-Garcia, C., \& Benavides-Velasco, C.A. (2008). Innovative competence, exploration and exploitation: the influence of technological diversification. Research Policy, 37, 492-507.

Roberts, E. (1980). New ventures for corporate growth. Harvard Business Review, 58(4), 134-142.

Roberts, P.W., \& McEvily, S. (2005). Product-line expansion and resource cannibalization. Journal of Economic Behavior \& Organization, 57, 49-70.

Sitken, S.B. (1996). Learning through failures: The strategy of small losses. In M.D. Cohen and L.S. Sproull (Eds.), Organizational Learning (pp. 541-577). Thousand Oaks, CA: Sage.

Takayama, M., Watanabe, C., \& Griffy-Brown, C. (2002). Alliance strategy as a competitive strategy for successively creative new product development: the proof of the coevolution of creativity and efficiency in the Japanese pharmaceutical industry. Technovation, 22, 607-614.

Thomke, S., \& Kuemmerle, W. (2002). Asset accumulation, interdependence and technological change: evidence from pharmaceutical drug discovery. Strategic Management Journal, 23, 619-635.

Tidd, J., \& Taurins, S. (1999). Learn or leverage? Strategic diversification and organizational learning through corporate ventures. Creativity and Innovation Management, 8(2),122129.

Tonkens, R. (2005). An overview of the drug development process. Physician Executive, 31(3), 48-52.

World Health Organization Collaborating Centre for Drug Statistics Methodology. The Anatomical Therapeutic Chemical (ATC)/ Defined Daily Dose (DDD) classification system index. Retrieved from http://www.whocc.no/atcddd/

Zahay, D., Griffin, A., \& Fredericks, E. (2011). Information use in new product development: an initial exploratory empirical investigation in the chemical industry. Journal of Product Innovation Management, 28(4), 485-502.

Zahra, S.A., \& George, G. (2002). Absorptive capacity: a review, reconceptualization, and extension. Academy of Management Review, 27(2), 185-203.

Zander, U., \& Kogut, B. (1995). Knowledge and the speed of the transfer and imitation of organizational capabilities. Organization Science, 6(1), 76-92. 